\title{
Climate change mitigation in Local Area Agreements: an enforced lack of ambition?
}

\author{
Will Eadson* \\ Sheffield Hallam University
}

\begin{abstract}
The introduction of carbon emissions monitoring to the new local government national indicator set marks the first attempt by the UK Government to spatially regulate action on climate change mitigation at the sub-national level. In the latest round of the linked Local Area Agreements 100 local authorities and Local Strategic Partnerships have adopted targets based on area-wide emissions reductions; seemingly a promising signal of local intent across England. However, under further inspection of the targets agreed, the methodology used, the methods employed and the monitoring process, the purported ambition of the Government to drastically cut carbon emissions is brought into question; as is the wider aim of granting local authorities greater freedoms.
\end{abstract}

Keywords: Local government, climate change, targets, modernisation.

\section{Introduction}

In June 2008, 150 Local Area Agreements (LAAs) agreed between central government, regional Government Offices and Local Strategic Partnerships (LSPs) - led by local authorities - across England were published. These constituted the third phase of LAAs, following pilots and gradual roll-out across the country since 2004 . These agreements consisted of up to 35 targets taken from a (slimmed down) list of 198 National Indicators used in the Local Authority Comprehensive Performance Assessment (CPA; to be renamed Comprehensive Area Assessment in 2009). Of particular interest here is the inclusion within the National Indicator set of two climate change mitigation indicators, the more ambitious measure - NI 186 - monitoring carbon emissions across a local authority area.

Defra made this measure their priority environmental indicator and it was made clear to regional Government Offices that they were to push for its inclusion in LAAs (GO Yorkshire and Humber, 2008): in all, 100 LAAs included the measure, with a further 30 agreeing to the less ambitious $\mathrm{NI} 185$, which aims to reduce local authority 'in-house' 
emissions. At a glance this provides an encouraging snap-shot of climate change mitigation action in England: keenness from central government to embed, or 'mainstream', climate change mitigation across scales of governing, effectiveness of Government Offices in implementing the wishes of central government, and willingness of LSPs/local authorities to take action.

Such a view, however, masks a range of matters for concern regarding the construction and implementation of NI 186. Firstly, the agreed targets are shown to be lacking ambition on a number of fronts. Local authorities have agreed to, on the whole, very similar targets, suggesting that few have aimed to stretch themselves. This is compounded when compared to data produced by AEA Energy and Environment (2008) suggesting that few LAA targets have aimed to go as far as implementation of the most basic measures would achieve, as well as the fact that the targets, in effect, cover a 5 year period; two years longer than the 'official' implementation period.

Most importantly, the efficacy of the targets is brought into question by (a) the methodology used, (b) the scales at which suggested measures are aimed, (c) the types of measures used and (d) the inability to measure progress against targets. Both local authorities and Government Offices are also seen to have had very little room to manoeuvre with regard to agreeing to differing approaches or measurement methodologies, and the supposed devolution of power to the local level is in fact shown to be more ambiguous, with devolved responsibility paradoxically matched with increased central control. Although it would be interesting, as well as potentially fruitful, to provide a deeper analysis of the contextual issues affecting NI 186 take-up, the key aim of this discussion is to explore the efficacy of the indicator in itself. As such, exploring other, more contingent factors of the decision-making process are kept to a minimum here. It is, however, hoped that this discussion will lead to further avenues of research in this area.

\section{UK Climate Change Targets}

The UK government is committed by the Kyoto Protocol through the EU15 bloc of countries to reduce its GHG (the so called 'basket of six' greenhouse gases) emissions by 12.5 per cent by 2008-2012 (baseline 1990). On coming to power in 1997 the Labour Party also introduced a target of 20 per cent reduction in $\mathrm{CO}_{2} \mathrm{e}\left(\mathrm{CO}_{2}\right.$ equivalent $)$ emissions by 2010 (baseline 1990); recent iterations have expressed this target as 2008-12, in line with Kyoto timescales. The UK Climate Change Bill, proclaimed by the Government as the 'first of its kind in any country' (DEFRA, 2007), was introduced to Parliament in July 2007 and is due to be granted Royal Assent during the Autumn 2008 Parliamentary sitting. It is the first time emissions targets are to be enshrined in national law, and as such perhaps signals a move towards the hardening of climate change policy at the national level. The draft Bill states that 'It is the duty of the Secretary of State to ensure that the net UK carbon account for the year 2050 is at least 60 per cent lower than the 1990 baseline' (para 1, line 5-6), although it does allow for changes to be made to this: in his most recent 're-launch' speech at the September 2008 Labour Party Conference, Gordon Brown pledged to increase this to 80 per cent to match the most recent IPCC headline figures. This has been matched by a commitment from the new Climate Change and Energy Minister, Ed Miliband, to amend the Climate Change Bill to reflect this pledge, as well as include previously excluded aviation and shipping emissions (The Guardian, 27th October 2008). Moves towards monitoring local delivery in fact precede the Bill, with the 2006 Local Government White Paper (CLG, 2006b) committing to developing appropriate local climate change indicators. It is these targets, and an implicit aim to ensure that that all levels of government are seen to be 'doing their bit' that have provided the backdrop 
for moves by the Government towards greater local authority engagement with the climate change agenda; including debates around the implementation of disaggregated emissions targets to regional and local governing bodies (c.f. Environmental Audit Committee, 2008).

\section{Local Area Agreements}

The incremental emasculation of local government throughout the 1979-1997 Conservative Government left local authorities stripped of power and heavily straitjacketed in areas where power did remain: so much so that in 1997 the Congress of Local and Regional Authorities of the Council of Europe (CLRAE) listed the UK as one of just six Council of Europe countries with 'serious deficiencies' in the practice of local democracy (Resolution 58, in Game, 2002 p406); the others being Bulgaria, Croatia, Latvia, Moldova and Ukraine. A key tenet of the New Labour Government's agenda on coming to power was a 'modernisation' agenda aimed at reforming various aspects of government, including the management of the public sector. Changes to local government, and the central-local relationship, were key strands within this programme of reform, aimed at revitalising local democracy and service delivery (Andrews et al., 2005).

According to many, including Rhodes (2000) and Newman (2001), this modernisation process in fact continued the trends set by the previous Conservative Government, through strengthening the neo-liberal reforms of the preceding 18 years, but also including a search for new forms of accountability to users and stakeholders; a search for 'citizen centred governance' (Benington, 2000). Such reforms used market mechanisms, but also relied on strengthening the regulatory capacity of the state, as a result of which '[p]erformance indicators ... are now viewed as an essential instrument of political control' (Newman, 2001 p88). It should, however, be noted that this programme has not centred around shrinkage of local government: in the period 19982007 Local Government financing rose at a level above inflation every year (CLG 2007c), the capacities of local authorities have increased (Martin, 2002), and certain operational flexibilities have been afforded (Pratchett, 2004).

In 1999, the Local Government Act introduced the Best Value regime as 'the centrepiece' (Martin, 2000 p211) of this programme, focussing on local authority service provision. Comprehensive Performance Assessment was introduced in 2002, through which the Audit Commission monitor the performance of local authorities against - amongst other, more qualitative measures - a range of National Indicators. A proliferation of policies aimed at monitoring through targets and indicators continued throughout the second and third terms of the New Labour Government: by 2006 local authorities were required to report on more than 1200 performance indicators on an annual basis (CLG, 2007a) through Comprehensive Performance Assessment and Best Value Performance Indicators. In a bid to streamline the monitoring process a new National Indicator set was introduced in 2008, which reduced the number of mandatory indicators to 198, with Ruth Kelly, then Minister for Communities and Local Government stating that:

For the last ten years, the improvements in our public services have been driven largely from the centre ... But ... we must have the courage at the centre to let go. The challenges we face are too complex, the needs often too local, for all solutions to be imposed from the centre. (Kelly, 2006) 
The development of Local Area Agreements in 2004 - which culminated in nationwide roll-out in 2008 - whereby Local authorities, with their LSPs, agree up to 35 targets based on the National Indicator set, has been championed as a means of furthering this ambition, CLG (2008) claiming that 'LAAs are helping to devolve decision making, move away from a "Whitehall knows best" philosophy and reduce bureaucracy...There will be no other way of setting targets, no other way of Whitehall managing local authority performance'. Furthermore, and more deeply embedding the apparent commitment to a 'new localism' (Coaffee and Headlam, 2008):

Setting the targets will be the subject of genuine negotiation between central Government and the local area. Whitehall will not mandate them. Even where targets are set out for Public Service Agreements at national level, local areas will have the flexibility to respond to these national ambitions in the most appropriate way in negotiation with Government Offices. (CLG, 2007a)

Marking a first for the UK, the new National Indicator (NI) set included performance monitoring of local authority contributions to climate change mitigation and adaptation: $\mathrm{NI} 185$ refers to local authority 'in-house' carbon emissions; NI 186 to local authoritywide emissions, NI 187 - a somewhat tenuous link to climate change - to fuel poverty, and $\mathrm{NI} 188$ to climate change adaptation. Here the focus is on mitigation, specifically $\mathrm{NI} 186$, which is the first example of mandatory spatial emissions reporting in the UK.

In attempting to match the Government's rhetoric on its purported goal of drastically cutting climate change emissions with delivery, this discussion will focus on four areas of analysis. Firstly the level of take up of $\mathrm{NI} \mathrm{186,} \mathrm{and} \mathrm{the} \mathrm{targets} \mathrm{agreed,} \mathrm{will} \mathrm{be}$ examined, followed by a look at the measurement methodology, suggested measures to achieve the targets and finally, monitoring. In doing so wider debates touched upon above will come under scrutiny, in particular, the Government's commitment to 'flexibility' and 'empowerment' of local governing structures.

\section{NI 186 Take-up and Targets}

Of 150 LAAs agreed in 2008, 87 per cent (130) included at least one climate change mitigation target, a seemingly encouraging statistic. 100 included NI 186, and of those that did not, a further 30 included NI 185 (local authority 'in-house' emissions). Furthermore, of the remaining 20 LAAs, 13 included $\mathrm{NI} 188$ (Climate Change Adaptation measures), of which 10 are coastal areas or with tidal rivers, and so may quite reasonably see adaptation as their priority in light of predictions of rising sea levels. This leaves just seven LAAs with no climate change measures, disregarding NI 187.

An initial point to make is that NI 185 seems a strange indicator for an area-wide agreement: LAAs are supposed to be about local authorities working in partnership with LSPS to deliver change across their geographical remit, not just achieving in-house improvements. There is an argument that the indicator may be used to demonstrate local authority leadership on climate change mitigation or as a preparation for building capacity towards implementing $\mathrm{NI} 186$ at a later date, but $\mathrm{NI} 185$ should not necessarily be seen as a positive step by local authorities: it is likely that the majority will be included in the forthcoming Carbon Reduction Commitment, which will place a legal imperative on organisations with an electricity usage of over $6,000 \mathrm{mWh} / \mathrm{yr}$ (Carbon Trust, 2008) to reduce emissions through a cap and trade scheme. It is for these reasons that NI 185 has been excluded from the remainder of this discussion, as well as the desire to focus on local authorities' powers to affect change within their spatial remit. So, to look at it from the other angle, a third of local authorities chose 
not to include a mitigation target that involved instigating action outside of their own activities; seemingly a very high non-adoption rate for an indicator Defra had highlighted as the priority environmental indicator.

Turning now to those LAAs that have included NI 186, Table 1, below, shows the key descriptive statistics for the targets agreed.

Table 1: NI 186 Targets for $\mathrm{CO}_{2}$ e Reductions in 'Take-Up' LAAs (Baseline 2005)

\begin{tabular}{lrrrrr}
\hline & Mean & Median & Max & Min & Standard Deviation \\
\hline $2008-11(n=95)$ & $10.5 \%$ & $11.0 \%$ & $15.0 \%$ & $1.0 \%$ & $2.2 \%$ \\
$2008-9(n=87)$ & $3.7 \%$ & $3.4 \%$ & $11.8 \%$ & $0.0 \%$ & $2.0 \%$ \\
$2009-10(n=86)$ & $3.2 \%$ & $3.3 \%$ & $7.0 \%$ & $0.0 \%$ & $1.2 \%$ \\
$2010-11(n=86)$ & $3.7 \%$ & $3.7 \%$ & $11.0 \%$ & $0.6 \%$ & $1.5 \%$ \\
\hline
\end{tabular}

In all, local authorities and LSPS (henceforth referred to jointly as local authorities) have pledged to cut emissions by 26.429 mega-tonnes, equal to a 5.7 per cent reduction of total UK carbon emissions as measured through the indicator, or a 4.7 per cent reduction in the UK's total 'Kyoto' carbon emissions in 2005. This would provide quite a boost to the UK's carbon accounts; as of $2005 \mathrm{CO}_{2} \mathrm{e}$ emissions had fallen by just 6.2 per cent - having actually risen since Labour came to power in 1997 (Helm et al., 2007) - and so NI 186 contributions would come close to doubling that in just three years. Assuming no drastic measures taken elsewhere, however, this would still see carbon emissions reductions drifting a long way short of New Labour's aspirational target of 20 per cent reductions by 2010 , or even as stated in more recent iterations by 2008-2012. Nonetheless, to achieve such a reduction through implementation of $\mathrm{NI}$ 186 would appear to be quite an achievement.

Delving slightly deeper, however, this apparently bright scenario begins to cloud over. In a study by AEA Energy and Environment for Defra (2008) it was suggested that through the implementation of 'principle' measures - consisting entirely of measures that are nationally-led, with some requiring local input (see below) - 134 of the 150 higher tier local authority areas in England would achieve $\mathrm{CO}_{2} \mathrm{e}$ emissions reductions of greater than 10 per cent by 2010 (baseline 2005). In practice, only three LAAs Windsor and Maidenhead, Newcastle Upon Tyne and Kirklees - aim to achieve 10 per cent reductions by 2010 across all of the local authorities, although 60 LAAs do aim for more than a 10 per cent reduction over the full length of the target period. In total, only 20 of the 100 LAAs aim for greater reductions than those suggested by AEA to take place as a result of the implementation of 'Principle' indicators (those for which there is sufficiently robust data; see below), all of which are measures implemented at the national level, or implemented nationally but with some local influence.

Taken as a whole then, the level of up-take and agreed targets present, if not a gloomy picture, then one which deeply lacks ambition. Yet this only scratches the surface. Turning to the methodology used further highlights the lack of ambition involved, as well as the presence of the Government's continuing centrist tendencies even when 'empowering' others, including the problems this causes in attempting to achieve change. 


\section{Methodology}

$\mathrm{NI} 186$ employs a measurement methodology that uses 'point-source' emissions data and includes only carbon emissions. This is in line with the methodology adopted through the forthcoming Climate Change Bill, and so in terms of governmental accounting makes a degree of sense. In addition, this makes it easier to monitor data, as ostensibly the data is already readily available (although, see 'monitoring' below). In one sense then, any critique of UK, EU and UNFCCC methodologies (c.f. Helm et al. 2008; Kerr, 2007) could apply to this methodology, but there are some additional concerns that arise when looking at the local level. Taking the most notorious example, the exclusion of international air travel and shipping from accounting, local authorities with an airport within their boundaries will be no more hindered in meeting their reductions than those without. More widely, the point-source approach does not include 'embedded' emissions - that is, those that have been incurred in transporting or producing goods prior to their consumption within the local authority area. As such, those areas engaging in alternative, consumption-based, approaches to climate change mitigation, such as localisation of food production, may find themselves actually increasing their measured emissions.

Similarly, restricting emissions to carbon may help to meet UK-wide targets, but limits the responses that local authorities can make. One of the biggest responsibilities, and indeed powers, held by local authorities relates to waste and waste disposal. Here potentially large reductions to waste-related emissions (for example, methane) could be made, but will not be measured. This methodology is part of the indicator itself and as such is compulsory for those LAAs that adopt targets based upon it. Neither Government Offices nor local authorities have any room for manoeuvre on this issue. As such, this is likely only to limit the experimentation and use of alternative approaches to emissions reduction that are necessary to achieving future progress.

\section{Measures to achieve reductions}

The Analysis to Support Climate Change Indicators in local authorities report (AEA, for Defra, 2008) is cited as the key source of guidance for local authorities adopting NI 186 by Defra (2008). The report develops the indicator and predicted savings through drawing up a list of measures that can be taken to reduce emissions to meet NI 186 targets. Local authority suggested targets have been based upon taking these actions. As alluded to above, the large majority of measures included within this report are not locally-led programmes at all. Of 51 suggested measures, only seven are listed as 'purely local measures implemented by LAs [local authorities] or other organisations', while 19 are 'purely national measures'; the remainder are 'national measures but can be improved in performance with influence by LAs' (AEA, 2008 p36). These measures are, on the whole, reductions that can be made through Government programmes that are already in progress. Local authorities will already be expected to aid with the implementation of the large majority of schemes listed, whether they take up the indicator or not. Table 2, below, shows the 'purely local' measures suggested. 
Table 2: Purely local measures implemented by LAs or other organisations

\begin{tabular}{lll}
\hline Measure Name & Sector & Measure Group \\
\hline $\begin{array}{l}\text { Smarter choices } \\
\begin{array}{l}\text { Restrictive measures on } \\
\text { transport use }\end{array}\end{array}$ & Transport & Sensitivity \\
$\begin{array}{l}\text { Vehicle maintenance (tyre } \\
\text { pressure etc) }\end{array}$ & Transport & Gap \\
$\begin{array}{l}\text { Driver training (behavioural } \\
\text { measures) }\end{array}$ & Transport & Gap \\
$\begin{array}{l}\text { Municipal clean fleet switch } \\
\text { Measures that can be used to } \\
\text { reduce sprawl }\end{array}$ & Transport & Gap \\
\hline
\end{tabular}

Source: AEA (2008)

Note: measure group applies to the robustness of available data: 'gap' data is that for which there is no reliable data; 'sensitivity' where there is data, but with a 'lack of robustness'.

As can be seen, the measures are confined to actions relating to transport, and for those which no reliable data is available at present. This contrasts to the 'purely national' measures, which span across all sectors under consideration (business, public sector, domestic and transport) and for which there is previously published, 'reasonably reliable' data (AEA, 2008 p36). In the absence of data for these seven measures it would be unfair to dismiss them out of hand as unable to contribute significantly to overall emissions reduction, but it might be reasonable to suggest that driver training and vehicle maintenance are unlikely to be the - excuse the pun - driving force behind climate change mitigation, and while 'measures that can be used to reduce sprawl' might offer gains, the title is too vague to know exactly what is being referred to. On the other hand, switching to municipal 'clean fleets' - depending on the definition of 'clean' - could be a more positive move; although this is an 'in-house' measure and as such would presumably come under the Carbon Reduction Commitment and/or NI 185. Some clue to the role of local measures might be seen in the small number of LAAs that have included the local contribution to their over-arching target. The mean reduction as a result of local measures for the 12 LAAs is 3.13 per cent, although it is not clear in these whether only 'purely local' measures are taken into account. It would appear then, that the local authority contribution to meeting their own targets lie largely in aiding the implementation of national measures. As shown in Table 3, below, according to the AEA data 'national with local influence' measures account for only a quarter of the total savings made (including only those measures where data is available). While is difficult without detailed analysis of each individual measure to tell how far 'local influence' stretches, even in a situation where local authorities were entirely responsible for their implementation this is still a relatively small contribution to what is supposedly a local indicator.

Table 3: Contribution of measures to reductions

\begin{tabular}{lr}
\hline Measures & Savings (\% of total) \\
\hline Local & $2.8 \%$ \\
National w. local influence & $25.9 \%$ \\
National & $71.2 \%$ \\
\hline
\end{tabular}

Note: data available for only one of seven 'local' variables 
The identification of measures to achieve NI 186 targets brings the rationale behind the indicator into further question. While one might postulate that it is simply a case of Defra making the best of what data they have available in developing the indicator, the inclusion of so many - or indeed any - 'purely national' measures is puzzling. This, combined with the way in which measures have been suggested through a top-down process of dissemination, leads to a strengthening of a sense of the Government attempting to devolve responsibility for reducing carbon emissions, whilst retaining the powers to do so. In other words, local authorities are potentially a convenient scapegoat for national failure.

\section{Monitoring}

Moving on to the monitoring process, further central control is highlighted, whilst paradoxically - also bringing into question the Government's commitment to ensuring targets are met: adding credence to the evolving notion of what might be termed an enforced lack of ambition in LAAs. In the absence of published guidance or data on this issue, responses from a recent tranche of interviews with local authority officers in the Yorkshire and the Humber, South West and North East Government Office regions have been used. First and foremost, there is the key issue of measuring whether reductions are a result of local action or just a serendipitous by-product of a seemingly unrelated event (see Helm et al. (2007) for a view on the role of the UK's economic restructuring in reducing GHG emissions and on the manipulation of methodologies). As one respondent complained:

How can it really be measured? For instance if one big business closes in the area - say xxxxxx down the road - and his causes our emissions to fall, is that then us doing our job? Is that a success? ... There are a number of anomalies in the measurement. (County Council Officer, South West)

Secondly, there is a two to three year time lag in availability of data: targets refer to a 2005 baseline, and 2008 data is not expected to be available until the final year of the current agreements. This poses two problems for monitoring targets. Firstly, a number of 'carbon savvy' local authorities appear to have taken this opportunity to manipulate the process, by 'front-loading' their target, so that the 2008-9 year has the highest projected carbon reduction; including, as it does, any reductions made in the years 2005-8. The LAAs with higher reductions in their first year are then able to commit to much smaller commitments over the final two years of the programme; the mean target for these LAAs is only 0.5 per cent higher than for the other 'non-savvy' Agreements (see Table 4, below).

Table 4: NI 186 Targets for those local authorities where 2008-9 is the highest target year $(n=23)$

\begin{tabular}{lrrrrr}
\hline & Mean & Median & Max & Min & Standard Deviation \\
\hline $2008-11$ & $11.0 \%$ & $11.0 \%$ & $15.0 \%$ & $6.8 \%$ & $1.8 \%$ \\
$2008-9$ & $6.2 \%$ & $6.2 \%$ & $11.8 \%$ & $3.9 \%$ & $1.9 \%$ \\
$2009-10$ & $2.4 \%$ & $2.4 \%$ & $4.2 \%$ & $0.6 \%$ & $0.9 \%$ \\
$2010-11$ & $2.5 \%$ & $2.5 \%$ & $4.1 \%$ & $0.6 \%$ & $0.9 \%$ \\
\hline
\end{tabular}


In effect it may make little difference, depending on whether LAAs are judged on yearly or overall results, but it does highlight the point that NI 186 targets are in fact five years in length as opposed to the official three, with the likelihood that in some areas a chunk of the reductions will already have been made. The second issue, which, in the absence of any Defra publications, has been identified through comments made by local authority officers potentially renders the first obsolete. In negotiating the targets, a number of local authorities brought up the issue of the data time-lag and the fact that only a small period of the LAA - within the first year - can be quantitatively measured using Defra data. One respondent recounted his experience, saying that:

Defra and the Government Offices recognise that, recognise that it's a problem and have clearly said to us, because we've gone through the target setting process, that 'well we can't measure you, but we will be asking for a qualitative assessment of what you're doing on the possibility of those measures that are mentioned; that make up the 186 savings. (Local Authority Officer, North East)

So, whilst the overall success of the measures cannot therefore be easily monitored, the implementation of the measures set out by the AEA report can be. As such, the lack of ability to quantifiable measure the data results in local authorities being tied even more tightly to the top-down imposition of set measures.

Finally, it appears that there are few incentives to meet targets set, except for overall performance across the whole LAA. If there are any incentives, local authority and Government Office officers seem unaware of them, with the exception of some 'BREW' (Business Resource Efficiency and Waste) funding to all local authorities that have taken up NI 186. Similarly, there appear to be no direct consequences for failure to achieve emissions reductions through the indicator.

\section{Conclusions}

The points made here should seen as initial, indicative, findings rather than a definitive critique of LAAs and climate change mitigation. Further research is clearly needed into the experiences of local government officers, regional Government Office officers and Whitehall officials in order to develop a more comprehensive understanding of the process. However, in light of the findings revealed above it is possible some tentative conclusions.

First, it is perhaps not surprising that 50 local authorities/LSPs resisted government pressure to include the indicator; not necessarily because they do not see climate change mitigation as important, but that NI 186 in itself is wrought with faults and inconsistencies - discussions with regional policy officers suggest that, for example, Leeds, Middlesbrough and Somerset Councils have not taken up the indicator on these grounds - while the emerging picture of central government's implementation and measurement suggest a lack of real incentive for its adoption.

Jon Coaffee and Nicola Headlam $(2008, \mathrm{p} 1)$ suggest that Local Area Agreements are showing signs that 'local state management of national policy could be becoming

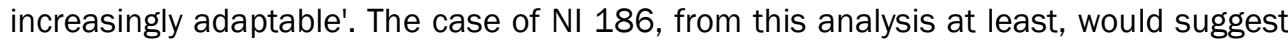
otherwise. It would be unfair to judge a whole regime on one aspect of its delivery - and given that this is only the first attempt at developing a local indicator for climate change mitigation, NI186 may indeed be special case - but if other LAA targets have been agreed in similar ways to $\mathrm{NI} 186$, the whole process lends a degree of mockery to the notion of a 'new settlement for local - national relations' (CLG, 2006). On the basis 
of this example, LAAs would not appear to be offering increased freedom to local authorities, but instead asking them to choose - from a limited selection - which areas they would like to be more heavily interfered with by central government.

Perhaps more importantly, this first step towards disaggregated spatial emissions targets suggests a skewed set of priorities for the Government. Responsibility is devolved to the local level, while the vast majority of powers to achieve the targets remain with national government. If one was being cynical, it might be suggested that this is simply a ploy for the Government to take credit for any successes and leave individual authorities with the blame for any failure. Not that success in meeting targets, on this evidence, will be any great achievement. The range of measures to be imposed through NI 186 represent a wholesale lack of ambition or willingness to experiment with different approaches to reducing emissions: in other words a failure to recognise Prime Minister Gordon Brown's (2007) own statement that avoiding catastrophic climate change 'must be the great project of this generation'.

Implicit within the disaggregation of spatial targets is an understanding that each level of governing has responsibility, but more importantly the potential, to assist with emissions reductions. Legally-binding, as well as aspirational, targets can have an important role in setting out goals and performance measures. They may be a necessary part of ensuring that emissions cuts are made across-the-board and not just in those areas that have taken a progressive attitude towards climate change. On the surface, inclusion of $\mathrm{NI} 186$ in Local Area Agreements appears to allow those progressive authorities the opportunity to work further towards meeting their ambitions and gain some recognition along the way. The downfall of this arrangement, however, is the fact that these authorities may in fact be penalised by Central Government by being given a constrained list of measures with which to work. Conversely, for those lagging areas that have taken up NI 186, either as a result of Governmental coercion, or in self-recognition of a need to improve their record there are no real incentives - be they 'carrot' or 'stick' - for them to achieve improvements, while the list of measures to be taken encourages very little by way of a step change in local operations.

\section{Acknowledgements}

Thanks to Peter Wells, Tony Gore and Chris Elton for comments and advice on earlier drafts as well as the various people in local and regional governing organisations who took part in informal and formal interviews. Responsibility for any errors or omissions in the paper remains with the author.

* Correspondence Address: Will Eadson, CRESR, Sheffield Hallam University, Unit 10, Science Park, Howard Street, Sheffield, S1 1WB. Email: w.eadson@shu.ac.uk.

\section{References}

AEA Energy and Environment (2008) Analysis to Support Climate Change Indicators for local authorities. London: DEFRA.

Andrews, R., Boyne, G A., Law, J. and Walker, R.M. (2005) External constraints on local service standards: the case of comprehensive performance assessment in English local government. Public Administration, 83, 3, 639-656.

Brown, G. (2007) Speech to WWF and Foreign Press Association. WWF Seminar, London, 19th November, 2007. 
p. 150. Climate Change Mitigation in Local Area Agreements: An Enforced Lack of Ambition?

Brown, G. (2008) Speech to Labour Party Conference. Labour Party Conference, Manchester, 23rd September 2008.

CLG (2006a) Better Services, Better Places Communities and Local Government Press Release, 13th December, 2006 http://www.communities.gov.uk/news/corporate /legalduty (accessed 27/9/08).

CLG (2006b) Strong and prosperous communities: the Local Government White Paper, http://www.communities.gov.uk/documents/localgovernment/pdf/154067.pdf (accessed 5/11/08).

CLG (2007a) The New Performance Framework for Local Authorities and Local Authority Partnerships: single set of national indicators. London: Communities and Local Government.

CLG (2007b) Planning Policy Statement: Planning and Climate Change: Supplement to Planning Policy Statement 1.

$\begin{array}{lllll}\text { CLG } & \text { (2007c) } & \text { Local } & \text { Government } & \text { Financial }\end{array}$ http://www.local.odpm.gov.uk/finance/stats/index.htm.

CLG (2008) Local Area Agreements www.commmunities.gov.uk.

Coaffee, J. and Headlam, N. (2008) Pragmatic localism uncovered: The search for locally contingent solutions to nation reform agendas. Geoforum, 39, 4, 15851599.

Defra (2008) Local Government Indicators http://www.defra.gov.uk/environment /localgovindicators/ni186.htm accessed 31/10/08.

Environmental Audit Committee (2008) Climate Change and local, regional and devolved Government. London: House of Commons Stationery Office

Game (2002) Britain's '5 Percent' Local Government Revolution: the faltering impact of New Labour's modernization agenda. International Review of Administrative Sciences, 68, 405- 417.

GO Yorkshire and Humber (2008) Local Area Agreement Climate Change Toolkit. Unpublished document.

Helm, D., Smale, R. and Phillips, J. (2007) Too Good To Be True? The UK's Climate Change Record. Oxford: Oxford University. http://globalisierungsklima.files. wordpress.com/2007/12/carbon_record_2007.pdf

Hencke, D. (2008) Minister bows to calls on climate change bill. The Guardian 27th October, 2008.

Kelly, R. (2006) Preface in Strong and Prosperous Communities: the Local Government White Paper. London: Department for Communities and Local Government.

Kerr, A. (2007) Serendipity is not a strategy: the impact of national climate programmes on greenhouse-gas emissions. Area, 39, 4, 418-430.

Martin, S. (2000) Implementing 'Best Value': Local Public Services in Transition. Public Administration, 78, 1, 209-227.

Martin, S. (2002) The modernization of UK local government: markets, managers, monitors and mixed fortunes. Public Management Review, 4, 3, $291-307$.

Newman, J. (2001) Modernising Governance: New Labour, Policy and Society. London: Sage.

Pratchett, L. (2004) Local autonomy, local democracy and the 'new localism'. Political Studies, 52, 358-375.

Rhodes, R.A.W. (2000) New Labour's civil service: summing-up joining up. The Political Quarter, 71, 151-166.

Wilson, J. (2004) Comprehensive performance assessment - springboard or deadweight? Public Money and Management, January 2004, 63- 68. 